\title{
Health of Spanish centenarians: a cross- sectional study based on electronic health records
}

\author{
Antonio Gimeno-Miguel ${ }^{1 * \dagger}\left(\mathbb{D}\right.$, Mercedes Clerencia-Sierra ${ }^{1,2 \dagger}$, Ignatios loakeim³ ${ }^{3}$, Beatriz Poblador-Plou', \\ Mercedes Aza-Pascual-Salcedo 1,4, Francisca González-Rubio 1,5, Raquel Rodríguez Herrero ${ }^{2}$ and \\ Alexandra Prados-Torres ${ }^{1}$
}

\begin{abstract}
Background: With the number of centenarians increasing exponentially in Spain, a deeper knowledge of their socio-demographic, clinical, and healthcare use characteristics is important to better understand the health profile of the very elderly.

Methods: We conducted a retrospective, cross-sectional observational study in the EpiChron Cohort (Aragón, Spain) aimed at analyzing the socio-demographic, clinical, drug use and healthcare use characteristics of 1680 centenarians during 2011-2015, using data from electronic health records and clinical-administrative databases.

Results: Spanish centenarians ( $79.1 \%$ women) had 101.6 years on average. Approximately $80 \%$ of centenarians suffered from multimorbidity, with an average of 4.0 chronic conditions; $50 \%$ were exposed to polypharmacy, with an average of 4.8 medications; only $6 \%$ of centenarians were free of chronic diseases and only $7 \%$ were not on medication. Centenarians presented a cardio-cerebrovascular pattern in which hypertension, heart failure, cerebrovascular disease and dementia were the most frequent conditions. Primary care was the most frequently visited healthcare level (79\% of them), followed by medical specialist consultations (23\%), hospitalizations (13\%), and emergency service use (9\%).
\end{abstract}

Conclusions: Multimorbidity is the rule rather than the exception in Spanish centenarians. Addressing medical care in the very elderly from a holistic geriatric view is critical in order to preserve their health, and avoid the negative effects of polypharmacy.

Keywords: Centenarians, Multimorbidity, Polypharmacy, Healthcare use, Spain

\section{Background}

The substantial decline in old age mortality of the past decades, together with the large birth cohorts of the early 1900s, has led to more and more people currently living beyond 100 years worldwide [1]. The United Nations, which monitors the global number of centenarians since 1990, stated that this age group will strongly increase from half a million

\footnotetext{
* Correspondence: agimenomi.iacs@aragon.es

${ }^{+}$Antonio Gimeno-Miguel and Mercedes Clerencia-Sierra contributed equally and served as first co-authors.

${ }^{1}$ EpiChron Research Group on Chronic Diseases, Aragon Health Sciences Institute (IACS), IIS Aragón, Miguel Servet University Hospital, REDISSEC, Paseo Isabel la Católica, 1-3, 50009 Zaragoza, Spain

Full list of author information is available at the end of the article
}

in 2015 to more than 25 million people in 2100 [2]. In Spain, their numbers are estimated to increase from 16,460 at present to more than 220,000 in 2066 [3].

Additionally, the rates of multimorbidity (i.e., presence of two or more chronic diseases) [4] and of its associated negative consequences such as higher risk of polypharmacy, disability and functional decline, and inappropriate healthcare use (e.g., hospitalizations by ambulatory care sensitive conditions, readmissions to hospital in a short period of time, overutilization of healthcare services) [5] could be expected to increase in centenarians as the burden of chronic diseases consistently grows with age [6-8]. Notwithstanding,

(c) The Author(s). 2019 Open Access This article is distributed under the terms of the Creative Commons Attribution 4.0 International License (http://creativecommons.org/licenses/by/4.0/), which permits unrestricted use, distribution, and reproduction in any medium, provided you give appropriate credit to the original author(s) and the source, provide a link to the Creative Commons license, and indicate if changes were made. The Creative Commons Public Domain Dedication waiver (http://creativecommons.org/publicdomain/zero/1.0/) applies to the data made available in this article, unless otherwise stated. 
centenarians have been described as a heterogeneous population group in terms of their morbidity profiles $[9,10]$ and health service use patterns [11], which might be explained in part by the dissimilar populations and methodologies used in the existing literature [12-14].

Some studies suggest that the burden of chronic conditions in centenarians is low, with low lethality rates $[10,15,16]$ and low healthcare use [17]. Richmond et al. [16] conducted a study based on structured health history questionnaires and reported a relatively low prevalence of chronic conditions, with many centenarians escaping cardiovascular disease, osteoporosis, dementia, respiratory illness, cancer, anxiety and depression. However, the positive results reported by Australian centenarians might be related in part to the fact that this study was based on self-perceived health information from a convenience sample with various recruitment methods. By contrast, the Danish Centenarian Study [9] showed high levels of morbidity, particularly in hypertension (52\%), dementia (51\%), ischemic heart disease (27\%), and strokes (22\%); and a study of Tokyoite centenarians [18] found that more than $95 \%$ of them had chronic diseases.

The most commonly reported diseases in centenarians vary among studies and countries, including chronic conditions and symptoms such as joint pain (64\%), hypertension (40-64\%), cataracts/ocular disease (47-71\%), arthritis (58\%), left ventricular dysfunction (54\%), heart disease (29-31\%), osteoporosis (28\%), gastrointestinal disease (21\%), depression (18\%), and cerebrovascular disease (16\%), and also conditions such as fractures $(47 \%)$ and dizziness $(44 \%)[16,18,19]$.

Understanding the health profile and health care needs of the very elderly and generally frail, such as centenarians, becomes especially relevant when considering their numbers are increasing exponentially. Although the more methodologically sound research studies reported high prevalence of chronic diseases and multimorbidity in centenarians, no studies on the health status or healthcare use of Spanish centenarians have been published in the English literature. With our data including almost all centenarians in a geographical region that is representative of the whole of Spain we expect to provide sound scientific knowledge to this field of study. This could facilitate the design of specific care models fitting the socio-demographic and clinical characteristics of centenarians, and the identification of potential underlying factors for shorter longevity. The aim of this study was to describe the socio-demographic, clinical and healthcare use characteristics of a cohort of Spanish centenarians using routinely collected data from electronic health records and clinicaladministrative databases.

\section{Methods}

\section{Design and study population}

We conducted a retrospective, cross-sectional observational study in the EpiChron Cohort [20]. This cohort links socio-demographic, clinical, health services use, and drug dispensation information for the public health system users of the Spanish region of Aragón (1.3 million inhabitants). The reference population of the EpiChron Cohort was 1,253,292 individuals at baseline (i.e., January 1, 2011), which represents approximately $98 \%$ of total inhabitants. The study population was composed of people from the cohort aged 100 years or more who were alive at some point in time from January 1, 2011 to December 31, 2015. The anonymized data used in the study was obtained from electronic health records and clinical-administrative databases linked at the patient level (i.e., user database, primary, specialist, hospital and emergency care, and pharmacy billing databases). A more detailed description of the cohort profile and of the data sources has been published elsewhere [20]. Only patients with at least one contact with the health system registered in their electronic health records were included in the study (Fig. 1).

The information analyzed included age, sex, area of residence (urban/rural), deprivation index of the area (according to 26 socioeconomic indicators) [21], all diagnoses of chronic diseases, all chronic medications dispensed, use of potentially inappropriate medications according to the updated Beers criteria [22], and healthcare use rates. All the information analyzed corresponded to the last 365 days of follow-up of each participant, which ended with either death of the patient, withdrawal of the system, or on December 31, 2015. Diagnoses were grouped in Expanded Diagnostic Clusters (EDCs) based on the Johns Hopkins ACG ${ }^{\circ}$ System (version 11.0, The Johns Hopkins University, Baltimore, MD, US). This classification system is useful in multimorbidity studies to count diseases when diagnoses from different sources and codification systems are used (e.g., ICPC-1 codes from primary care and ICD-9-CM codes from hospitals). For the analysis of multimorbidity, defined as the co-occurrence of two or more chronic diseases, we considered all 114 of the EDCs defined as chronic by Salisbury et al. [23]. We defined chronic medications as those with three or more dispensations over the 365-days follow-up period, using the Anatomical-TherapeuticChemical (ATC) classification system code at the third level. We calculated the anticholinergic drug scale score [24] and the anticholinergic cognitive burden [25] for each patient based on their medical prescriptions.

\section{Statistical analysis}

We performed a descriptive analysis of socio-demographic, clinical, healthcare use and drug use characteristics of 


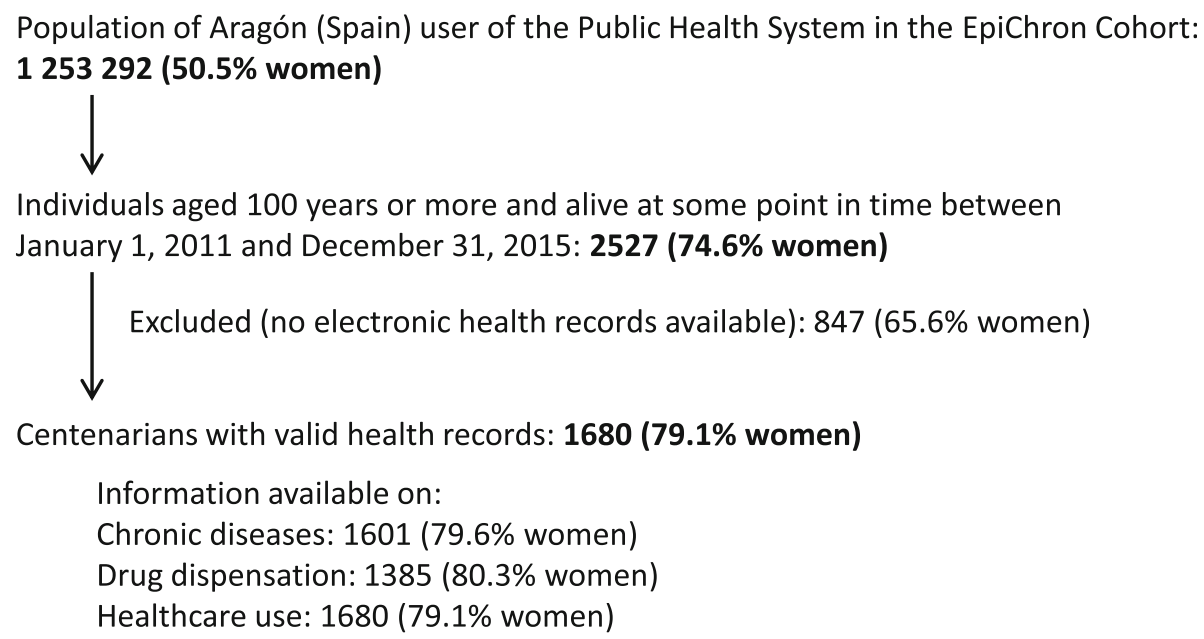

Fig. 1 Flowchart for the study population

centenarians, by sex. The results were calculated as means and/or frequencies accompanied by their 95\% confidence intervals. We used the Kruskal-Wallis test to compare means and the Pearson's chi-squared test to compare frequencies. Statistical significance was set at $p<0.05$. We conducted all the analyses in Stata (Version 12.0, StataCorp LLC, College Station, TX, US).

\section{Results}

\section{Demographics of centenarians}

A total of 1680 people $(79.1 \%$ women $)$ of the EpiChron Cohort were 100 years old or above at some point in time from January 1, 2011 to December 31, 2015 and had valid electronic health records. Their socio-demographic characteristics are shown in Table 1. They had an average age of 101.6 (standard deviation, s.d., 1.84) years, with no differences by sex. The maximum age registered was 111 years in women and 109 years in men. Two women were supercentenarians (i.e., 110 years old or older), and 32 men and 101 female were semi-supercentenarians (i.e., aged 105 years or more). Regarding their place of residence, $57 \%$ of centenarians lived in an urban area during the study period. Approximately $30 \%$ of them lived in the less deprived areas (i.e., Q1) according to the deprivation index calculated for each basic health area of the region.

\section{Disease burden in centenarians}

Centenarians showed an average disease burden of almost 4 chronic conditions with no differences by sex, and approximately $6 \%$ of them did not present any chronic condition (Table 1). The prevalence of multimorbidity reached $80 \%$ of the centenarian population.
The ten most frequently reported chronic conditions in centenarians were, regardless of their sex, hypertension (56.0\%), chronic ulcer of skin (28.1\%), cerebrovascular disease (21.5\%), congestive heart failure (20.3\%), dementia (19.9\%), degenerative joint disease (17.1\%), varicose veins of lower extremities (14.9\%), cataract/ aphakia (13.9\%), cardiac arrhythmia (11.7\%), and diabetes (11.1\%; Table 2). Incontinence was present in $49.5 \%$ of centenarians. The prevalence of some cardiovascular risk factors, such as hypertension and lipid metabolism disorders, as of other conditions such as chronic ulcer of the skin, dementia, degenerative joint disease, varicose veins, and osteoporosis was higher in women. On the other hand, men showed higher prevalence rates of COPD, other respiratory disorders, gout, and low back pain.

\section{Drug use in centenarians}

Centenarians presented a mean treatment burden of 4.8 chronic medications (Table 1), and $49.5 \%$ of them received five or more drugs (i.e., polypharmacy). Only 7\% of centenarians had no chronic medications dispensed. According to the updated Beers criteria from 2015 [22] and to anticholinergic scores [24], centenarians received on average 1.35 potentially inappropriate medications, $8 \%$ of them were treated with high anticholinergic risk drugs, and $11 \%$ suffered a high anticholinergic cognitive burden, with no differences by sex.

Gastroprotective drugs (50.9\%), antithrombotic agents (40.6\%), analgesics and antipyretics (36.0\%), diuretics (34.2\%), anxiolytics (21.5\%), antidepressants (14.4\%), hypnotics-sedatives (13.8\%), antipsychotics (13.6\%), and ACE (angiotensin converting enzyme) inhibitors (13.4\%) were the most frequently dispensed chronic drugs in centenarians (Table 3). The dispensation of anxiolytics, hypnotics-sedatives, and opioids, among others, was 
Table 1 Socio-demographic, clinical and healthcare use characteristics of centenarians, by sex. Means are accompanied by their 95\% confidence intervals in brackets

\begin{tabular}{|c|c|c|c|}
\hline & Men & Women & $P$ value \\
\hline \multicolumn{4}{|l|}{ Socio-demographics } \\
\hline $\mathrm{N}$ & 351 & 1329 & $<0.001$ \\
\hline Mean age, years ${ }^{\mathrm{a}}$ & $101.7(101.5-101.9)$ & $101.6(101.5-101.7)$ & n.s. \\
\hline Urban residence, \% & $58.7 \%$ & $56.7 \%$ & n.s. \\
\hline Deprivation index, $\%^{c}$ & & & n.s. \\
\hline Q1 & $29.1 \%$ & $31.1 \%$ & \\
\hline Q2 & $23.7 \%$ & $22.8 \%$ & \\
\hline Q3 & $24.0 \%$ & $20.7 \%$ & \\
\hline Q4 & $23.1 \%$ & $25.6 \%$ & \\
\hline \multicolumn{4}{|l|}{ Clinical information } \\
\hline Without chronic diseases, \% & $7.6 \%$ & $5.2 \%$ & n.s. \\
\hline Chronic diseases, mean ${ }^{a}$ & $3.97(3.65-4.28)$ & $3.97(3.81-4.12)$ & n.s. \\
\hline With multimorbidity, \% & $78.0 \%$ & $81.3 \%$ & n.s. \\
\hline Without chronic medications, \% & $8.1 \%$ & $6.4 \%$ & n.s. \\
\hline Chronic drugs, mean $^{\mathrm{a}}$ & $4.94(4.56-5.33)$ & $4.77(4.58-4.95)$ & n.s. \\
\hline With polypharmacy, \% ${ }^{\mathrm{d}}$ & $49.8 \%$ & $49.5 \%$ & n.s. \\
\hline With potentially inappropriate medications, \% $\%$,e & $71.1 \%$ & $72.3 \%$ & n.s. \\
\hline Potentially inappropriate medications, mean ${ }^{a}$ & $1.32(1.19-1.45)$ & $1.36(1.29-1.43)$ & n.s. \\
\hline Anticholinergic Drug Scale score, \% & & & n.s. \\
\hline 0 & $50.6 \%$ & $50.2 \%$ & \\
\hline 1 & $28.2 \%$ & $29.5 \%$ & \\
\hline 2 & $12.4 \%$ & $12.3 \%$ & \\
\hline$\geq 3$ & $8.8 \%$ & $8.0 \%$ & \\
\hline Anticholinergic Cognitive Burden score, \% & & & n.s. \\
\hline 0 & $55.3 \%$ & $52.3 \%$ & \\
\hline 1 & $26.0 \%$ & $28.8 \%$ & \\
\hline 2 & $6.2 \%$ & $8.5 \%$ & \\
\hline$\geq 3$ & $12.5 \%$ & $10.4 \%$ & \\
\hline \multicolumn{4}{|l|}{ Healthcare use } \\
\hline Users of primary care services, $\%$ & $76.1 \%$ & $79.4 \%$ & n.s. \\
\hline Visits to GPf mean $^{\mathrm{a}}$ & $10.6(9.4-11.7)$ & $10.8(10.2-11.5)$ & n.s. \\
\hline Visits to nurse, mean ${ }^{a}$ & $9.3(7.8-10.9)$ & $12.1(10.9-13.3)$ & n.s. \\
\hline Users of specialities, \% & $24.5 \%$ & $22.3 \%$ & n.s. \\
\hline Visits to a specialist, mean ${ }^{a}$ & $2.79(2.16-3.43)$ & $2.72(2.44-2.99)$ & n.s. \\
\hline Different specialties visited, mean ${ }^{a}$ & $1.37(1.23-1.51)$ & $1.47(1.37-1.57)$ & n.s. \\
\hline Users of hospital, \% & $14.8 \%$ & $12.1 \%$ & n.s. \\
\hline Total hospital admissions, mean ${ }^{a}$ & $1.35(1.17-1.52)$ & $1.34(1.23-1.45)$ & n.s. \\
\hline Scheduled hospital admissions, mean ${ }^{a}$ & $0.06(0.00-0.12)$ & $0.12(0.06-0.17)$ & n.s. \\
\hline Length of stay in days, mean ${ }^{a}$ & $10.0(7.9-12.0)$ & $11.6(10.3-13.0)$ & n.s. \\
\hline Users of emergency room, \% & $11.7 \%$ & $8.3 \%$ & n.s. \\
\hline Visits to emergency room, mean ${ }^{a}$ & $1.80(1.40-2.21)$ & $1.45(1.28-1.62)$ & n.s. \\
\hline
\end{tabular}

${ }^{a}$ A non-parametric test was used; ${ }^{b}$ Not statistically significant; ${ }^{c}$ From less (Q1) to most (Q4) deprived administrative health areas; ${ }^{d}$ Defined as five or more drugs dispensed; ${ }^{\mathrm{e} A c c o r d i n g}$ to Beers criteria; ${ }^{\mathrm{f} G e n e r a l ~ P r a c t i t i o n e r ~}$ 
Table 2 Prevalence of chronic conditions in men $(n=351)$ and women $(n=1329)$ centenarians. Conditions are listed in descending order of total prevalence, and only those with prevalence equal to or greater than $1 \%$ are represented

\begin{tabular}{|c|c|c|c|c|}
\hline EDC ${ }^{a}$ code & Chronic condition & Men (\%) & Women (\%) & $P$ value \\
\hline CAR14/15 & Hypertension & 46.8 & 58.4 & $<0.001$ \\
\hline REC03 & Chronic ulcer of the skin & 22.0 & 29.7 & $<0.01$ \\
\hline NUR05 & Cerebrovascular disease & 22.3 & 21.3 & n.s. ${ }^{b}$ \\
\hline CAR05 & Congestive heart failure & 20.2 & 20.3 & n.s. \\
\hline NUR24 & Dementia & 12.8 & 21.7 & $<0.001$ \\
\hline MUSO3 & Degenerative joint disease & 13.2 & 18.1 & $<0.05$ \\
\hline GSU08 & Varicose veins of lower extremities & 8.6 & 16.5 & $<0.001$ \\
\hline EYE06 & Cataract, aphakia & 14.7 & 13.7 & n.s. \\
\hline CAR09 & Cardiac arrhythmia & 14.1 & 11.1 & n.s. \\
\hline END06/07/08/09 & Diabetes & 10.1 & 11.4 & n.s. \\
\hline EAR08 & Deafness, hearing loss & 8.6 & 10.9 & n.s. \\
\hline CAR11 & Disorders of lipid metabolism & 6.4 & 11.4 & $<0.05$ \\
\hline PSY19 & Sleep disorders of nonorganic origin & 8.9 & 10.8 & n.s. \\
\hline HEM02 & Iron deficiency, other deficiency anemias & 11.9 & 9.7 & n.s. \\
\hline EYE08 & Ischemic heart disease or $\mathrm{AMI}^{\mathrm{C}}$ & 11.6 & 9.1 & n.s. \\
\hline PSY09 & Glaucoma & 8.0 & 8.9 & n.s. \\
\hline END02 & Depression & 7.3 & 8.2 & n.s. \\
\hline CAR03 & Osteoporosis & 1.8 & 9.3 & $<0.001$ \\
\hline RESO4 & Emphysema, chronic bronchitis, COPD ${ }^{d}$ & 14.7 & 5.4 & $<0.001$ \\
\hline SKN02 & Dermatitis and eczema & 8.6 & 6.1 & n.s. \\
\hline HEM03 & Malignant neoplasms & 9.7 & 4.3 & $<0.001$ \\
\hline NUR21 & Thrombophlebitis & 3.4 & 5.8 & n.s. \\
\hline GURO4 & Neurologic disorders, other & 5.8 & 5.0 & n.s. \\
\hline RES11 & Prostatic hypertrophy & 24.2 & 0.0 & $<0.001$ \\
\hline EYE02 & Respiratory disorders, other & 7.0 & 4.2 & $<0.05$ \\
\hline MAL01 & Visual impairment & 5.5 & 4.6 & n.s. \\
\hline CAR16 & Skin/low impact neoplasms & 5.5 & 3.8 & n.s. \\
\hline END04 & Cardiovascular disorders, other & 3.1 & 3.9 & n.s. \\
\hline END05 & Hypothyroidism & 3.1 & 3.8 & n.s. \\
\hline REN01 & Other endocrine disorders & 1.8 & 4.1 & n.s. \\
\hline RHU02 & Chronic renal failure & 4.9 & 3.0 & n.s. \\
\hline NUT03 & Gout & 7.0 & 2.1 & $<0.001$ \\
\hline ADM02 & Obesity & 1.5 & 3.5 & n.s. \\
\hline CAR12 & Surgical aftercare & 3.4 & 2.8 & n.s. \\
\hline HEM08 & Hematologic disorders, other & 4.3 & 2.4 & n.s. \\
\hline ALL04/05 & Asthma & 1.5 & 3.1 & n.s. \\
\hline GAS10 & Diverticular disease of colon & 2.5 & 1.9 & n.s. \\
\hline PSY14 & Psychosocial disorders of childhood & 1.2 & 2.2 & n.s. \\
\hline PSY01 & Anxiety, neuroses & 1.2 & 2.0 & n.s. \\
\hline CAR06 & Cardiac valve disorders & 1.8 & 1.8 & n.s. \\
\hline MAL12 & Low back pain & 3.1 & 1.0 & $<0.05$ \\
\hline MUS14 & Irritable bowel syndrome & 0.9 & 1.3 & n.s. \\
\hline GAS09 & Seizure disorder & 2.1 & 1.0 & n.s. \\
\hline
\end{tabular}


Table 2 Prevalence of chronic conditions in men $(n=351)$ and women $(n=1329)$ centenarians. Conditions are listed in descending order of total prevalence, and only those with prevalence equal to or greater than $1 \%$ are represented (Continued)

\begin{tabular}{lllll}
\hline EDC $^{\text {a code }}$ & Chronic condition & Men (\%) & Women (\%) & $P$ value \\
\hline NUR07 & Utero-vaginal prolapse & 0.0 & 1.4 & 1.0 \\
FRE12 & Parkinson's disease & 1.5 & 1.2 & n.s. \\
NUR06 & Gastroesophageal reflux & 0.6 & 1.2 & n.s. \\
GAS08 & Peripheral neuropathy, neuritis & 0.6 & n.s. \\
\hline
\end{tabular}

${ }^{\mathrm{a}}$ From a list of 114 Expanded Diagnostic Clusters; ${ }^{\mathrm{b}}$ Not statistically significant; ${ }^{\mathrm{C}}$ Acute myocardial infarction; ${ }^{\mathrm{d}}$ Chronic obstructive pulmonary disease

higher in women compared with men; whereas the latter were prescribed more non-steroidal anti-inflammatory and antirheumatic products, antigout preparations, and inhalants for obstructive airway diseases and adrenergics.

\section{Healthcare use of centenarians}

Primary care was the most frequently visited level of care by centenarians. It was used by $79 \%$ of them, with an average of 11 annual visits to the General Practitioner (GP) and to the nurse (Table 1). Specialists were less frequently visited, and only $23 \%$ of centenarians received specialized care, with an average of 2.7 visits per year to 1.5 different specialities. The most visited specialists were radiologists (56.6\% of the visits to a specialist), ophthalmologists $(9.3 \%)$, orthopaedists and traumatologists (5.1\%), dermatologists (4.4\%), cardiologists (3.5\%), and endocrinologists, nutritionists and urologists (2.3\%), among others. More than $85 \%$ of centenarians did not require hospitalization during the study period. Those that used hospital care were admitted 1.3 times per year on average with a mean length of stay of 11 days. Unplanned hospitalizations were much more frequent than scheduled ones and represented $92.5 \%$ of the total number of hospitalizations. The ten most prevalent reasons for hospital admission were heart failure (in $12.0 \%$ of admissions), femoral neck fractures (10.0\%), other respiratory system diseases (9.4\%), pneumonia (6.5\%), occlusion of cerebral arteries (3.5\%), other lung diseases (3.5\%), pneumonitis due to solids and liquids (3.3\%), septicaemia $(2.5 \%)$, acute renal failure $(2.2 \%)$, and other urethral and urinary tract disorders (2.0\%). Approximately nine in ten centenarians did not require visiting the emergency room; the rest visited this service 1.5 times per year on average. Sex had no effect on the utilization of any healthcare service.

\section{Discussion}

This study describes the socio-demographic, clinical and healthcare use characteristics of 1680 Spanish centenarians of the EpiChron Cohort between 2011 and 2015 based on electronic health records and clinical-administrative data sources. As far as we know, this is the first study describing the health status of Spanish centenarians in the English literature using register-based health record data from a population-based cohort. As expected, the vast majority of people who reached age 100 were women [26].

Multimorbidity prevalence has been shown to increase as we get older [23, 27]. This concurs with the results from the EpiChron Cohort, where multimorbidity prevalence increased from $12 \%$ in the population aged $0-14$ years to 16,47 , and $80 \%$ in people aged 15-44, 45-64 and $\geq 65$ years, respectively [20]. According to this trend, one might have expected multimorbidity prevalence in centenarian populations to be above the $80 \%$ observed in the present study. However, our results do not necessarily indicate a lower-than-expected burden of chronic diseases, and could just signify physical and/or environmental difficulties in accessing health care services, or a 'laissez-faire' attitude or ageism [28] that could ultimately result in lower diagnosis rates.

Medical literature regarding the prevalence of centenarians without a diagnosis of common chronic conditions is inconsistent. In the Danish Centenarian Study [9] the authors found that only one out of 207 subjects was free of actual diseases or chronic conditions. A Japanese study found it to be less than 3\% [18], another study reported that $19 \%$ of centenarians did not present chronic diseases [10], and yet another study found that $23 \%$ of centenarians reached age 100 with no major chronic diseases [29]. The proportion of disease-free centenarians in our study (6\%) is within this range, nonetheless, these figures should be interpreted with caution, since previous studies apply varying methodologies and approach sample recruitment and condition analysis differently. In our study, we used a comprehensive list of more than 100 diseases, in contrast with the lists used by other authors [10, 29]. Additionally, data sources were of great importance when interpreting the results. Electronic health records offered an objective method of patient clinical characterization through the diagnosis of previously confirmed medical conditions by healthcare professionals. Nevertheless, although the public health system in Spain provides universal coverage, the absence of registered clinical information does not necessarily mean an absence of disease. Furthermore, health care service use for diagnostic or therapeutic purposes may have been rejected by a number of 
Table 3 Prevalence of most dispensed chronic medications in men $(n=351)$ and women $(n=1329)$ centenarians. Drugs are listed in descending order of total prevalence, and only those with prevalence equal to or greater than $1 \%$ are represented

\begin{tabular}{|c|c|c|c|c|}
\hline ATC code & Chronic medication & Men (\%) & Women (\%) & $P$ value \\
\hline$\overline{A 02 B}$ & Drugs for peptic ulcer and GERD ${ }^{b}$ & 53.9 & 50.2 & n.s. ${ }^{c}$ \\
\hline B01A & Antithrombotic agents & 43.6 & 39.9 & n.s. \\
\hline N02B & Other analgesics and antipyretics & 34.1 & 36.4 & n.s. \\
\hline $\mathrm{CO3C}$ & High-ceiling diuretics & 31.5 & 34.9 & n.s. \\
\hline N05B & Anxiolytics & 13.9 & 23.4 & $<0.001$ \\
\hline N06A & Antidepressants & 12.8 & 14.7 & n.s. \\
\hline N05C & Hypnotics and sedatives & 9.9 & 14.7 & $<0.05$ \\
\hline N05A & Antipsychotics & 11.4 & 14.2 & n.s. \\
\hline CO9A & ACE $^{\mathrm{d}}$ inhibitors, plain & 7.3 & 14.9 & $<0.001$ \\
\hline B03A & Iron preparations & 12.8 & 10.7 & n.s. \\
\hline $\mathrm{CO8C}$ & Selective calcium channel blockers with mainly vascular effects & 13.9 & 10.3 & n.s. \\
\hline $\mathrm{CO5C}$ & Capillary stabilizing agents & 4.4 & 11.4 & $<0.05$ \\
\hline C01D & Vasodilators used in cardiac diseases & 8.1 & 10.3 & n.s. \\
\hline CO9C & Angiotensin II receptor blockers, plain & 7.0 & 9.0 & n.s. \\
\hline M02A & Topical products for joint and muscular pain & 6.1 & 9.0 & n.s. \\
\hline CO9D & Angiotensin II receptor blockers, combinations & 5.9 & 8.4 & n.s. \\
\hline S01E & Antiglaucoma preparations and miotics & 7.7 & 7.3 & n.s. \\
\hline A06A & drugs for constipation & 8.1 & 6.7 & n.s. \\
\hline M01A & Antiinflammatory and antirheumatic products, non-steroids & 10.3 & 6.1 & $<0.05$ \\
\hline C01A & Cardiac glycosides & 8.1 & 6.6 & n.s. \\
\hline N06B & Psychostimulants, agents used for $\mathrm{ADHD}^{\mathrm{e}}$ and nootropics & 8.8 & 6.0 & n.s. \\
\hline R05C & Expectorants, excl. Combinations with cough suppressants & 8.4 & 5.5 & n.s. \\
\hline $\mathrm{A} 10 \mathrm{~B}$ & Blood glucose lowering drugs, excl. Insulins & 5.1 & 5.9 & n.s. \\
\hline V06X & General nutrients & 5.5 & 5.6 & n.s. \\
\hline B03B & Vitamin B12 and folic acid & 5.1 & 5.5 & n.s. \\
\hline C07A & Beta blocking agents & 4.4 & 5.7 & n.s. \\
\hline N02A & Opioids & 2.2 & 6.2 & $<0.05$ \\
\hline G04C & Drugs used in benign prostatic hypertrophy & 26.0 & 0.0 & $<0.001$ \\
\hline C10A & Lipid modifying agents, plain & 6.6 & 4.3 & n.s. \\
\hline C04A & Peripheral vasodilators & 5.5 & 4.1 & n.s. \\
\hline R03A & Adrenergics, inhalants & 7.3 & 3.7 & $<0.05$ \\
\hline R03B & Other drugs for obstructive airway diseases, inhalants & 7.3 & 3.7 & $<0.05$ \\
\hline So1X & Other ophthalmologicals & 3.7 & 4.4 & n.s. \\
\hline CO9B & ACE inhibitors, combinations & 3.7 & 4.3 & n.s. \\
\hline D01A & Antifungals for topical use & 4.0 & 4.2 & n.s. \\
\hline C03D & Potassium-sparing agents & 5.9 & 3.6 & n.s. \\
\hline CO3E & Diuretics and potassium-sparing agents in combination & 1.1 & 4.6 & $<0.05$ \\
\hline A03F & Propulsives & 1.1 & 4.1 & $<0.05$ \\
\hline R06A & Antihistamines for systemic use & 5.5 & 3.1 & n.s. \\
\hline C01E & Other cardiac preparations & 3.7 & 3.4 & n.s. \\
\hline C03B & Low-ceiling diuretics, excl. Thiazides & 2.6 & 3.6 & n.s. \\
\hline C08D & Selective calcium channel blockers with direct cardiac effects & 3.7 & 2.7 & n.s. \\
\hline $\mathrm{A} 12 \mathrm{~A}$ & Calcium & 0.7 & 3.3 & $<0.05$ \\
\hline
\end{tabular}


Table 3 Prevalence of most dispensed chronic medications in men $(n=351)$ and women $(n=1329)$ centenarians. Drugs are listed in descending order of total prevalence, and only those with prevalence equal to or greater than 1\% are represented (Continued)

\begin{tabular}{lllll}
\hline ATC ${ }^{\text {c code }}$ & Chronic medication & Men (\%) & Women (\%) & $P$ value \\
\hline A12B & Potassium & 1.8 & 3.1 & n.s. \\
D07A & Corticosteroids, plain & 4.8 & 2.3 & $<0.05$ \\
M04A & Antigout preparations & 5.9 & 2.0 & 3.0 \\
N03A & Antiepileptics & 1.8 & 2.6 & n.s. \\
N07C & Antivertigo preparations & 2.9 & 1.9 & n.s. \\
J01 M & Quinolone antibacterials & 4.0 & 1.7 & n.s. \\
H02A & Corticosteroids for systemic use, plain & 3.7 & 2.3 & n.s. \\
H03A & Thyroid preparations & 1.1 & 1.4 & n.s. \\
J01X & Other antibacterials & 2.9 & 1.4 & n.s. \\
J01C & Beta-lactam antibacterials, penicillins & 2.6 & 1.6 & n.s. \\
N06D & Anti-dementia drugs & 1.8 & 1.4 & n.s. \\
V06Z & General nutrients & 2.9 & 1.7 & n.s. \\
S01A & Antiinfectives & 0.7 & 1.4 & n.s. \\
A10A & Insulins and analogues & 1.5 & 1.4 & n.s. \\
C03A & Low-ceiling diuretics, thiazides & 0.7 & 1.4 & n.s. \\
J01D & Other beta-lactam antibacterials & 1.1 & n.s. \\
R05D & Cough suppressants, excl. Combinations with expectorants & 2.3 & n.s. \\
H03B & Antithyroid preparations & 0.7 & n.s. &
\end{tabular}

${ }^{a}$ Anatomical Therapeutic Chemical Classification System; ${ }^{b}$ Gastroesophageal reflux disease; ${ }^{c}$ Not statistically significant; ${ }^{d}$ Angiotensin-converting-enzyme;

${ }^{\mathrm{e}}$ Attention deficit hyperactivity disorder

centenarians. In the Danish Centenarian Study [9] all participants (including proxies) were visited at their domicile for an interview, and further health information was retrieved from medical files and national health registers.

The most frequent diseases observed in centenarians vary among studies. The high prevalence of cardiovascular diseases found in our study is, however, a common finding, and has also been reported in 72 and $40 \%$ of Danish and New England centenarians, respectively $[9,10]$. Some of the diseases from the cardio-cerebrovascular disease pattern showed by our centenarians (i.e., hypertension, heart failure, cerebrovascular disease, and cardiac arrhythmia) have also been reported in other studies as the most prevalent in this age group. Hypertension prevalence was similar in Spanish, Danish and Japanese centenarians $[9,18]$, while heart failure prevalence was lower in our study compared to that reported by Danish and Canadians $[9,17]$. Cardiovascular and cerebrovascular diseases are the only frequent conditions in our study that associate high mortality rates $[10,15]$. The prevalence of diabetes mellitus in our centenarians (11\%) was similar to the $6-10 \%$ reported by other authors despite using different methodologies [9, 10, 18]. High dementia prevalence is also a common finding in centenarians [30], especially in women [17], whereas chronic ulcers of the skin are more likely to be a consequence of prolonged limitations in mobility as a result of underlining disorders.

According to our findings, one in two centenarians was polymedicated. The most frequently dispensed medications were similar to those in a Swedish study of community dwelling centenarians [31]. The proportion of individuals in our study with no drug prescriptions (7\%) was similar to the $5 \%$ found in the Danish Study [9]. A study conducted in the United Kingdom (UK), with an observation period of over twenty years using a Primary Care database of 11,000 individuals who reached the age of 100 , reported that $27 \%$ of centenarians had no drug prescriptions [32]. The mean burden of treatment in our centenarians, however, was lower, maybe because we only included chronic medication. It is also worth noting that our centenarians were treated with drugs with a low anticholinergic load. Despite all that, the percentage of individuals receiving inappropriate medication according to the Beers criteria was double when comparing with the UK study [32].

Some of the differences between men and women in our results regarding drug dispensation could be reasonably attributed to gender-related morbidities, while others could suggest unequal treatment of specific conditions (i.e., gender inequalities) [33]. For example, the overprescription of certain drugs, such as anxiolytics and hypnotics, was greater in women than in men, even 
though there were no significant differences in the prevalence of sleep disorders or anxiety/neuroses when stratifying by sex. Similarly, women were more often treated for pain with stronger analgesics, like opioids, when comparing with men.

Healthcare use in centenarians was lower than expected by age regardless of the level of care analyzed. The relatively low burden of chronic diseases and medications in centenarians resulted, as expected, in less intensive use of medical services [34]. These findings could even suggest a more appropriate pattern of healthcare use in centenarians, who mainly resorted to primary care instead of specialized care, and were not frequent users of emergency services. Our results are similar to those found in a previous study based on administrative health data of 1842 Canadian centenarians, who used primary care, hospital care and emergency services in 95, 18 and $26 \%$ of cases, respectively [17]. However, these results should be interpreted with caution as they might be explained in part by physical and/or environmental difficulties faced by these patients in accessing health care services.

\section{Strengths and limitations of the study}

The main strength of this study is that it draws on a population-based cohort representative of the Spanish population, although only users of the public health system with available electronic health records were considered for inclusion. As our main limitation, data used in the study was anonymized and centenarians could not be contacted to collect extra variables related to longevity that could have been of interest for the purposes of this study, such as lifestyle habits (e.g., smoking habit, alcohol consumption), level of physical functioning (e.g., activities of daily living), and biological, educational, and socioeconomic (e.g., housing conditions) indicators. Instead, data came from electronic health records and clinical-administrative databases, which, while constituting primary sources of clinical information, were not primarily designed for research purposes and, consequently, could entail some errors during the registration process.

\section{Conclusions}

The utilization of electronic health records allowed for the characterization of the health profile and healthcare use of Spanish centenarians. Multimorbidity seems to be the rule rather than the exception in this population, which mainly presented a cardio-cerebrovascular pattern including hypertension, heart failure, cerebrovascular disease, dementia, and skin ulcers. Addressing medical care in the very elderly from a holistic geriatric view is critical in order to preserve their health, and avoid the negative effects of polypharmacy. Future studies aimed at characterizing the health profile and longevity determinants of centenarians should also take into account genetic, environmental and socioeconomic factors as well as lifestyle habits and physical functionality.

\section{Abbreviations}

ACE: angiotensin-converting-enzyme; AMl: acute myocardial infarction; ATC: Anatomical-Therapeutic-Chemical; CEICA: Clinical Research Ethics Committee of Aragón; COPD: chronic obstructive pulmonary disease; EDCs: Expanded Diagnostic Clusters; ER: emergency room;

GERD: gastroesophageal reflux disease; GP: General Practitioner; s.d: standard error

\section{Acknowledgements}

This work was supported by Gobierno de Aragón [B01_17R] and the European Regional Development Fund "Construyendo Europa desde Aragón". The authors sincerely thank Eva Giménez Labrador for her statistical support and Kevin Bliek Bueno for his writing assistance.

\section{Authors' contributions}

APT and MCS conceived and designed the research. BPP generated and curated the database and conducted the statistical analyses. FGR, MAPS, MCS, AGM, APT and II interpreted the data. AGM, MCS, II and RRH drafted the manuscript. All authors read and approved the final manuscript.

\section{Funding}

This work was supported by Gobierno de Aragón [B01_17R] and the European Regional Development Fund "Construyendo Europa desde Aragón". The funders played no role in the design of the study, collection, analysis, and interpretation of data, or preparation of the manuscript.

\section{Availability of data and materials}

The datasets generated and analyzed during the current study are not publicly available due to the possibility of compromising individual privacy because of the small number of participants included, but are available from the corresponding author on reasonable request.

\section{Ethics approval and consent to participate}

This study was approved by the Clinical Research Ethics Committee of Aragón (CEICA, PI17/0024). The CEICA waived the requirement to obtain the informed consent from patients since the information used was anonymized.

Consent for publication

Not applicable.

\section{Competing interests}

The authors declare that they have no competing interests.

\section{Author details}

${ }^{1}$ EpiChron Research Group on Chronic Diseases, Aragon Health Sciences Institute (IACS), IIS Aragón, Miguel Servet University Hospital, REDISSEC, Paseo Isabel la Católica, 1-3, 50009 Zaragoza, Spain. ${ }^{2}$ Aragon Health Service (SALUD), Miguel Servet University Hospital, Zaragoza, Spain. ${ }^{3}$ EpiChron Research Group on Chronic Diseases, IIS Aragón, Zaragoza, Spain.

${ }^{4}$ Directorate of Primary Care, SALUD, Zaragoza, Spain. ${ }^{5}$ Primary Care Health Centre Delicias-Sur, SALUD, Zaragoza, Spain.

Received: 9 January 2019 Accepted: 30 July 2019

Published online: 19 August 2019

\section{References}

1. Rasmussen SH, Andersen-Ranberg K, Thinggaard M, et al. Cohort profile: the 1895, 1905, 1910 and 1915 Danish birth cohort studies - secular trends in the health and functioning of the very old. Int J Epidemiol. 2017;46:1746.

2. United Nations Department of Economic and Social Affairs. World population prospects: the 2015 revision. New York, US, 2015.

3. Instituto Nacional de Estadística. Proyecciones de Población 2016-2066. Madrid, Spain, 2016. 
4. Kingston $A$, Robinson $L$, Booth $H$, Knapp $M$, Jagger C. Projections of multi-morbidity in the older population in England to 2035: estimates from the population ageing and care simulation (PACSim) model. Age Ageing. 2018;47:374-80

5. Marengoni A, Angleman S, Melis R, et al. Aging with multimorbidity: a systematic review of the literature. Ageing Res Rev. 2011;10:430-9.

6. Fortin M, Bravo G, Hudon C, Vanasse A, Lapointe L. Prevalence of multimorbidity among adults seen in family practice. Ann Fam Med. 2005:3:223-8

7. Barnett K, Mercer SW, Norbury M, Watt G, Wyke S, Guthrie B. Epidemiology of multimorbidity and implications for health care, research, and medical education: a cross-sectional study. Lancet. 2012;380:37-43.

8. Fabbri E, Zoli M, Gonzalez-Freire M, Salive ME, Studenski SA, Ferrucci L. Aging and multimorbidity: new tasks, priorities, and Frontiers for integrated Gerontological and clinical research Multi-morbidity: Implications and Challenges for Medical Care and Research. J Am Med Dir Assoc. 2015;16:640-7.

9. Andersen-Ranberg K, Schroll M, Jeune B. Healthy centenarians do not exist, but autonomous centenarians do: a population-based study of morbidity among Danish centenarians. J Am Geriatr Soc. 2001;49:900-8.

10. Evert J, Lawler E, Bogan H, Perls T. Morbidity profiles of centenarians: survivors, delayers, and escapers. J Gerontol A Biol Sci Med Sci. 2003;58:232-7.

11. Menotti A, Blackburn H, Seccareccia F, et al. The relation of chronic diseases to all-cause mortality risk - the seven countries study. Ann Med. 1997;29:135-41.

12. Poon LW, Jazwinski M, Green RC, et al. Methodological considerations in studying centenarians: lessons learned from the Georgia centenarian studies. Annu Rev Gerontol Geriatr. 2007;27:231-64.

13. Vestergaard S, Andersen-Ranberg K, Skytthe A, Christensen K, Robine J-M, Jeune B. Health and function assessments in two adjacent Danish birth cohorts of centenarians: impact of design and methodology. Eur J Ageing. 2016;13:15-23

14. Rasmussen SH, Andersen-Ranberg K. Health in centenarians. In: Pachana NA, editor. Editor. Encyclopedia of Geropsychology. Singapore: Springer Science+Business Media Singapore; 2016. p. 13.

15. Beregi $E$, Klinger $A$. Health and living conditions of centenarians in Hungary. Int psychogeriatrics. 1989;1:195-200

16. Richmond RL, Law J, KayLambkin F. Morbidity profiles and lifetime health of Australian centenarians. Australas J Ageing. 2012;31:227-32.

17. Rochon PA, Gruneir A, Wu W, et al. Demographic characteristics and healthcare use of centenarians: a population-based cohort study. J Am Geriatr Soc. 2014;62:86-93.

18. Takayama M, Hirose N, Arai Y, et al. Morbidity of Tokyo-area centenarians and its relationship to functional status. J Gerontol A Biol Sci Med Sci. 2007;62:774-82.

19. Rasmussen SH, Andersen-Ranberg K, Dahl JS, et al. Diagnosing heart failure in centenarians. J Geriatr Cardiol. 2019;16:1-11.

20. Prados-Torres A, Poblador-Plou B, Gimeno-Miguel A, et al. Cohort profile: the epidemiology of chronic diseases and multimorbidity. The EpiChron cohort study. Int J Epidemiol. 2018;47:382-384f.

21. Compés Dea ML, Olivan Bellido E, Feja Solana C, Aguilar Palacio I, GarcíaCarpintero Romero del Hombrebueno G, Adiego Sancho B. Construction of a deprivation index by basic healthcare area in Aragon using population and housing census 2011. Rev Esp Salud Publica. 2018;92:1-17.

22. The American Geriatrics Society 2015 Beers Criteria Update Expert Panel. American Geriatrics Society 2015 updated beers criteria for potentially inappropriate medication use in older adults. J Am Geriatr Soc. 2015;63:2227-46.

23. Salisbury C, Johnson L, Purdy S, Valderas JM, Montgomery AA. Epidemiology and impact of multimorbidity in primary care: a retrospective cohort study. Br J Gen Pract. 2011;61:e12-21.

24. Carnahan RM, Lund BC, Perry PJ, Pollock BG, Culp KR. The anticholinergic drug scale as a measure of drug-related anticholinergic burden: associations with serum anticholinergic activity. J Clin Pharmacol. 2006;46:1481-6.

25. Boustani M, Campbell N, Munger S, Maidment I, Fox C. Impact of anticholinergics on the aging brain: a review and practical application. Aging Health. 2008;4:311-20.

26. Hazra NC, Dregan A, Jackson S, Gulliford MC. Differences in health at age 100 according to sex: population-based cohort study of centenarians using electronic health records. J Am Geriatr Soc. 2015;63:1331-7.

27. Tetzlaff J, Muschik D, Epping J, Eberhard S, Geyer S. Expansion or compression of multimorbidity? 10-year development of life years spent in multimorbidity based on health insurance claims data of Lower Saxony, Germany. Int J Public Health. 2017;62:679-86.
28. Wyman MF, Shiovitz-Ezra S, Bengel J. Ageism in the health care system: providers, patients, and systems. Cham: Springer; 2018. p. 193-212.

29. Ailshire JA, Beltrán-Sánchez H, Crimmins EM. Becoming centenarians: disease and functioning trajectories of older US adults as they survive to 100. J Gerontol A Biol Sci Med Sci. 2015;70:193-201.

30. von Berenberg P, Dräger D, Zahn T, Neuwirth J, Kuhlmey A, Gellert P. Chronic conditions and use of health care service among German centenarians. Age Ageing. 2017;46:939-45.

31. Wastesson JW, Parker MG, Fastbom J, Thorslund M, Johnell K. Drug use in centenarians compared with nonagenarians and octogenarians in Sweden: a nationwide register-based study. Age Ageing. 2012;41:218-24.

32. Hazra NC, Dregan A, Jackson S, Gulliford MC. Drug utilization and inappropriate prescribing in centenarians. J Am Geriatr Soc. 2016;64:1079-84.

33. Loikas D, Wettermark B, von Euler M, Bergman U, Schenck-Gustafsson K. Differences in drug utilisation between men and women: a cross-sectional analysis of all dispensed drugs in Sweden. BMJ Open. 2013;3:e002378.

34. Palladino R, Tayu Lee J, Ashworth M, Triassi M, Millett C. Associations between multimorbidity, healthcare utilisation and health status: evidence from 16 European countries. Age Ageing. 2016;45:431-5.

\section{Publisher's Note}

Springer Nature remains neutral with regard to jurisdictional claims in published maps and institutional affiliations.
Ready to submit your research? Choose BMC and benefit from:

- fast, convenient online submission

- thorough peer review by experienced researchers in your field

- rapid publication on acceptance

- support for research data, including large and complex data types

- gold Open Access which fosters wider collaboration and increased citations

- maximum visibility for your research: over $100 \mathrm{M}$ website views per year

At BMC, research is always in progress.

Learn more biomedcentral.com/submissions 